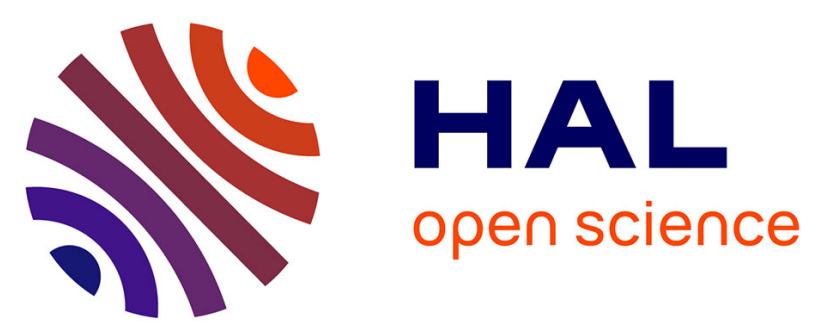

\title{
Discrete Element Simulations of 4-Point Bending Fatigue Tests of Asphalt Concrete Samples Reinforced by Fiber glass Grids
}

Guixian Liu, Georg Koval, Cyrille Chazallon

\section{To cite this version:}

Guixian Liu, Georg Koval, Cyrille Chazallon. Discrete Element Simulations of 4-Point Bending Fatigue Tests of Asphalt Concrete Samples Reinforced by Fiber glass Grids. 9th MairePAV conference, Jul 2020, Dübendorf (on line), Switzerland. 10.1007/978-3-030-48679-2_62 . hal-03243979

\section{HAL Id: hal-03243979 \\ https://hal.science/hal-03243979}

Submitted on 31 May 2021

HAL is a multi-disciplinary open access archive for the deposit and dissemination of scientific research documents, whether they are published or not. The documents may come from teaching and research institutions in France or abroad, or from public or private research centers.
L'archive ouverte pluridisciplinaire HAL, est destinée au dépôt et à la diffusion de documents scientifiques de niveau recherche, publiés ou non, émanant des établissements d'enseignement et de recherche français ou étrangers, des laboratoires publics ou privés. 


\title{
Discrete element simulations of 4-point bending fatigue tests of asphalt concrete samples reinforced by fiberglass grids
}

\author{
G. Liu ${ }^{1}$, G. Koval ${ }^{1, ~}{ }^{*}$ and C. Chazallon ${ }^{1}$ \\ ${ }^{1}$ ICUBE Laboratory, CNRS, National Institute of Applied Sciences of Strasbourg, \\ 24 Boulevard de la Victoire,Strasbourg 67084, France \\ georg.koval@insa-strasbourg.fr
}

\begin{abstract}
This paper studies the fatigue damage of asphalt concrete (AC) under strain controlled load. The 3-phase fatigue life is reproduced by the proposed simulations combining a 2-phase fatigue damage law and the discrete element method (DEM) characterized by discrete force and displacement on each contact. The simulation results present good agreements with experiments after the parameter calibrations. The reinforcement effect of fiberglass grids on the fatigue life of asphalt concrete is studied with 4-point bending (4PB) fatigue test. These preliminary results comparing simulations and experiments show the consistency of the proposed 2D model on describing part of the interactions between grids and asphalt concrete.
\end{abstract}

Keywords: fatigue, damage, discrete element, four-point bending, asphalt concrete

\section{Introduction}

Repeated traffic loads induce fatigue solicitation of the pavement structure. Accurate predictions of the effect of a very large number of loading cycles $\left(10^{5}-10^{6}\right)$ over the components of the pavements is a major requirement for the optimization and design of transport infrastructures.

At laboratory scale, alternate cyclic bending tests intend to quantify deflection effects. The results of stiffness degradation $\left(E_{n} / E_{0}, E_{n}\right.$ is the present sample modulus and $E_{0}$ is the original modulus) with respect to the cycle numbers obtained in a typical cyclic loading test can be divided into three phases (Zheng et al. 2019, Arsenie et al. 2017). In the first phase, the defects exist and micro cracks are created in the matrix between the aggregates. In the second phase, the cracks grow and connect. In the third phase, the cracks interconnect. The sample loses its homogeneity and large cracks appear and propagate unstably with an increasing rate.

The fatigue damage causes large amount of maintenance cost. Thus, the reinforcement of the asphalt concrete (AC) is widely studied by researchers (Guo et al, 2015; Ge et al, 2015; Nguyen et al, 2013). In the last decade, the reinforcement by fiberglass grids 
has been applied to improve the mechanical response of pavement structure materials. $\mathrm{Hu}$ and Walubita (2009) indicate that fiberglass grid helps to distribute the stress and prevent crack propagation from top to bottom and the opposite direction. They may dissipate stress concentrations due to reflection and fatigue cracks, and work as moisture barriers (Nguyen et al, 2013), which significantly reduces the damage and improves the service life. However, there is still a lack of research describing how the grid works in AC under fatigue load.

The aim of this research is to analyze laboratory experimental results of Arsenie (2013, 2017), which deals with 4-point bending (4PB) tests of reinforced and non-reinforced AC samples by means of computer simulations. The originality of the study is to implement a simple law of 2 regimes proposed by Bodin $(2002,2004)$ for AC as a contact law in discrete element method (DEM). This modelling approach takes advantage of DEM to reproduce the heterogeneous microstructure and crack development in cemented materials (Nguyen et al, 2019).

Section 2 presents the experimental setup. The third section covers the fatigue model description and its implementation in DEM. Section 4 presents the material calibration obtained by the comparison with experimental results. In section 5 , the reinforcements are introduced on the model and the numerical results are discussed. Finally, in section 6 , the conclusions of the paper are summarized.

\section{Experimental setup}

During her study, Arsenie $(2013,2017)$ performed 4-point bending (4PB) fatigue tests intending to quantify the contribution of the fiberglass grids on the fatigue life of asphalt concrete samples.

The geometry of the specimen is presented in Fig. 1. The standard beam dimensions have been adapted in order to have three warp yarns in the width of the beam. Therefore, the standard beam dimensions have been increased in width, length and thickness. Each beam has a length $L=630 \mathrm{~mm}$, and a square cross section with height $h=100 \mathrm{~mm}$ and width $w=100 \mathrm{~mm}$. The layers are bonded with a bitumen emulsion. The specimens of experiments are separated into two categories: reinforced asphalt concrete and non-reinforced asphalt concrete. The fiber grids lay between the AC layers in the reinforced beams.

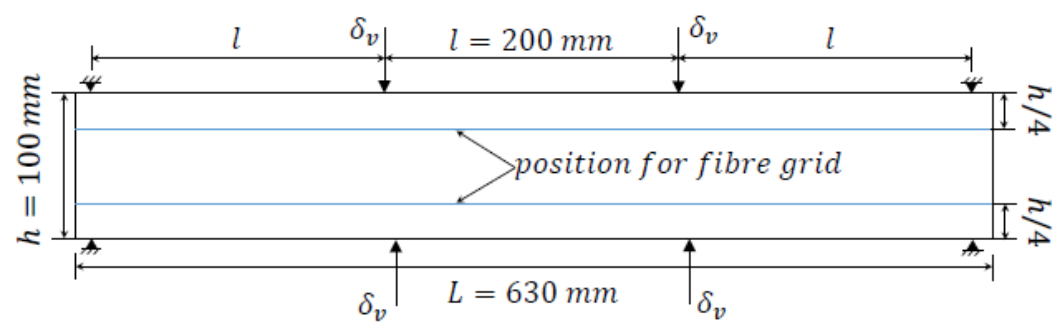

Fig. 1 Geometry of specimen for 4PB test performed by Arsenie $(2013,2017)$. 
A controlled strain condition is applied by the sinusoidal motion of the central supports as described in Fig. 2, which is the typical loading setup in fatigue of asphalt concrete (Partl et al, 2000). The reaction force on the supports $F_{v}$ also presents a sinusoidal response.

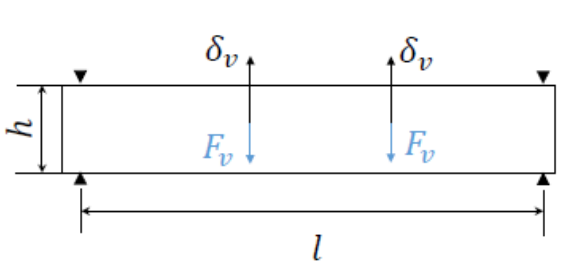

(a)

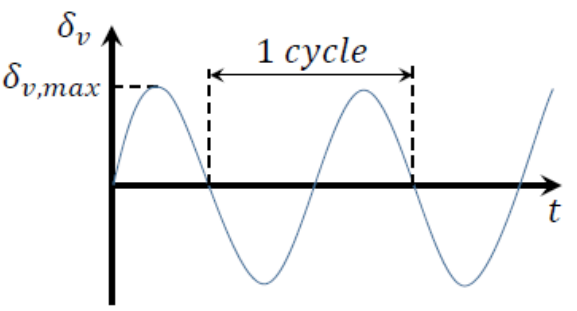

(b)

Fig. 2 Loading setup of the 4-point bending (4PB) tests performed by Arsenie $(2013,2017)$.

\section{Fatigue model and discrete element implementation}

\subsection{Local fatigue model}

The material fatigue damage $D$ is a state variable which characterizes the material mechanical condition. Its value ranges from 0 to $1(D=0$ indicates an intact material, whilst $D=1$ defines its complete failure).

\subsubsection{Rate of damage growth $\dot{D}$}

The rate of damage growth $\dot{D}$ is defined as

$$
\dot{D}=f(D) \tilde{\varepsilon}^{\beta}(\dot{\tilde{\varepsilon}})_{+},
$$

where $(\dot{\tilde{\varepsilon}})_{+}$is the positive value of the rate of increment of the local strain $\tilde{\varepsilon}$ (more details refer to Bodin 2002) and $\beta$ is a variable related to the fatigue slope $-1-\beta$ in $\log$-log scale. $f(D)$ is a function of the damage factor, which was proposed by Paas (1990) as

$$
f(D)=C D^{\alpha}
$$

where $C$ and $\alpha$ is a scalar parameter. According to Eq. (1), only a positive increment of strain may induce damage.

\subsubsection{Increment of damage $\delta D$ per cycle}

According to Eqs. (1) and (2), the damage is considered to be incremented only in tension and for positive strain rates. For a cyclic loading centered at zero, it represents the segments in Fig. 3 for $N_{C} \times T \leq t \leq N_{C} \times T+T / 4$, where $N_{C}$ is the number of cycles and $T$ is the period of the loading cycles. 


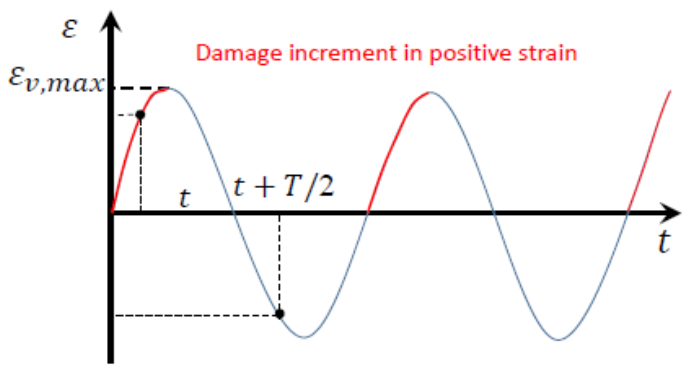

(a)

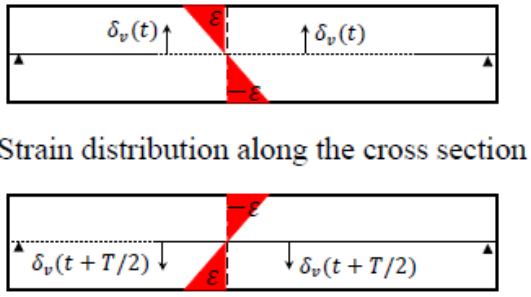

(b)

Fig. 3 Loading cycle contribution on damage increment.

Eq. (1) associated to Eq. (2) can be rewritten as

$$
\dot{D} / D^{\alpha}=C \tilde{\varepsilon}^{\beta}(\dot{\tilde{\varepsilon}})_{+}
$$

The local strain $\tilde{\varepsilon}$ induces damage increment only on the first quarter of the cycle, which means $(\dot{\tilde{\varepsilon}})_{+}=\dot{\tilde{\varepsilon}}$ for $0 \leq \mathrm{t} \leq \mathrm{T} / 4$. As shown more in detail in Liu (2019), for constant strain cycles, the evolution of the damage as a function of the number of cycles $N_{C}$ can be obtained by integration of Eq. (3) over the range of time $0 \leq \mathrm{t} \leq$ $N_{C} \times T$, which leads to

$$
D\left(N_{C}\right)^{1-\alpha} /(1-\alpha)=C N_{C} \varepsilon_{a}{ }^{1+\beta} /(1+\beta),
$$

where $\mathrm{D}\left(N_{C}\right)$ is the damage at $\mathrm{t}=N_{C} \times T$ and $\varepsilon_{a}$ corresponds to the amplitude of the local strain for a sinusoidal cycle. An incremental expression for damage can be obtained by derivation of Eq. (4) with respect to the number of cycles $N_{C}$

$$
\delta D / \delta N_{C}=C D^{\alpha} \varepsilon_{a}{ }^{1+\beta} /(1+\beta) .
$$

The value of damage $D$ must be initialized $(D=0)$. The value of the damage after the first cycle $D(1)$ can be obtained from Eq. (4) for $N_{C}=1$ :

$$
D(1)=\left[C(1-\alpha) \varepsilon_{a}^{1+\beta} /(1+\beta)\right]^{1 /(1-\alpha)}
$$

\subsection{DEM implementation of the fatigue model - Damage and force calculation}

In this study, the equivalent strain $\tilde{\varepsilon}$ of the simulation is obtained from the combination of the normal and tangential relative displacements $\left(\delta_{n}\right.$ and $\left.\delta_{s}\right)$ at the contact (for more details, see Liu, 2019). The amplitude of the local strain is consequently the maximum value of the local strain under cyclic loading $\varepsilon_{a}=\max (\tilde{\varepsilon})$. 
In the first cycle, the damage factor $D$ is initialized, being calculated for each contact by Eq. (6). At each new cycle, $D$ is modified incrementally, based on a first order solution of Eq. (5) as

$$
D\left(N_{C}+\Delta N_{C}\right)=D\left(N_{C}\right)+\Delta N_{C}\left[C D^{\alpha} \varepsilon_{a}{ }^{1+\beta} /(1+\beta)\right],
$$

where $\Delta N_{C}$ is the cycle increment parameter. Any value of $\Delta N_{C}>1$ allows a gain of calculation time, but must be carefully chosen not to induce cumulative errors. After the damage identification, normal and tangential forces can be updated as following

$$
\begin{aligned}
f_{n} & =k_{n}(1-D) \delta_{n}, \\
f_{s} & =k_{s}(1-D) \delta_{s},
\end{aligned}
$$

where $k_{n}$ and $k_{s}$ are the normal and tangential stiffness of the intact contacts, respectively. The fatigue model was programmed and compiled in $\mathrm{C}++$ language as part of the contact constitutive model implemented on the software PFC. For more information see reference Itasca (2014).

\subsection{Geometry and boundary conditions of 4-point bending (4PB) tests}

4PB tests are simulated by discrete element method (DEM). The geometry follows the dimensions of the experiments performed by Arsenie $(2013,2017)$ as indicated in Fig. 4a with length $L=630 \mathrm{~mm}$, height $h=100 \mathrm{~mm}$ and an equal spacing between supports $A=200 \mathrm{~mm}$. Experimentally (and numerically), supports 1 and 2 do not move, whilst supports 3 and 4 are driven by a cyclic centered displacement with an imposed amplitude $\delta_{v \text {, max }}$. The maximum normal strain level $\varepsilon_{\max }$ is observed in the middle section of the beam in upper and bottom positions and can be calculated by the expression (Arsenie, 2013)

$$
\delta_{v, \max }=(5 / 3)\left(A^{2} / h\right) \varepsilon_{\max }
$$

The reduced size of the supports, associated to free rotation prevent any undesired bending moment. The elastic distribution of efforts was verified comparing the results of the simulations to bending theory. However, the unrealistic dimensions of the support may induce a concentration of efforts which may lead to an inappropriate acceleration of the damage of the structure. This effect is avoided by the deactivation of the damage calculation $(D=0)$ inside a rectangular zone $(10 \mathrm{~mm} \times 15 \mathrm{~mm})$ around the supports (see Fig. 4b). This assumption does not cause any nonphysical behavior, such as a discontinuity on the damage field, because the supports are located in an area with very low damage during the simulations, as discussed in section 4.

The vertical force $F_{v}$, which correspond to the supports reactions, is measured during the fatigue tests. 


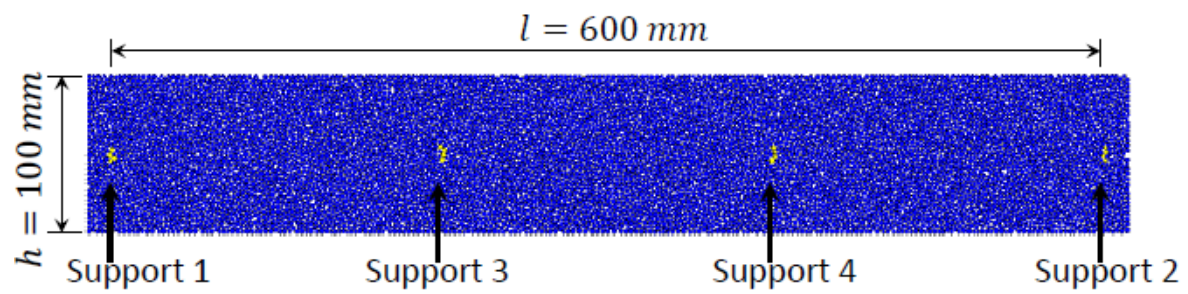

(a)

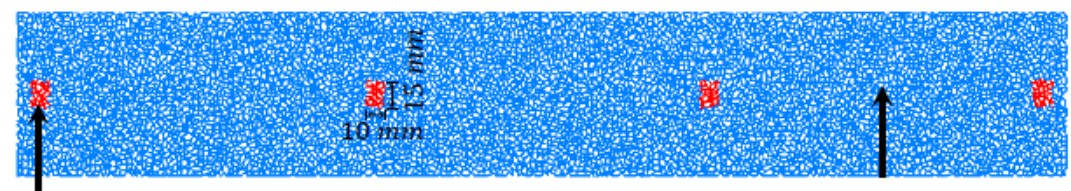

Undamageable contacts

damageable contacts

(b)

Fig. 4 Geometry of the 4PB samples in DEM. (a) Indication of the dimensions over the particle packing and (b) contact properties by zones.

\section{Calibration of the material parameters with experiments}

In the 4PB tests of Arsenie $(2013,2017)$, the strain level is driven by the value of maximum amplitude of the normal strain $\varepsilon_{\max }$ (obtained on the top and the bottom of the middle section). $\varepsilon_{\text {max }}$ is theoretically related to the vertical displacement of the central supports $\delta_{v}$ by Eq. (9). Respectively, on the simulations the values of $\delta_{v}$ of $76.7 \mu \mathrm{m}$ and $90 \mu \mathrm{m}$ are adopted. For the discrete element material description, the radius of particles follows a uniform distribution. The average value is $\bar{R}=2.9 \mathrm{~mm}$ and the size ratio $R_{\max } / R_{\min }=1.6$. The contact stiffness is $k_{n}=2.0 \times 10^{10} \mathrm{~N} / \mathrm{m}$, $k_{r}=4.5$, corresponding to a Young's modulus $E=11 \mathrm{GPa}$ and a Poisson's ratio $v=$ 0.34. The numerical results are obtained with an increment of cycles $\Delta N_{C}=100$, which leads to accurate and efficient calculations as presented in Liu (2019).

In Fig. 5, the experimental results of the stiffness fraction $F_{v} / F_{v 0}$ as a function of the number of cycles $N_{C}$ for $\varepsilon_{\max }=135 \mu \mathrm{m} / \mathrm{m}$ and $150 \mu \mathrm{m} / \mathrm{m}$ are presented. Here $F_{v 0}$ is the initial value of the reaction force $F_{v}$. The envelope curves with minimum and maximum values were obtained considering 6 different samples and show the relatively large variation of the experimental results. The average curves are the references for the calibration of the parameters of the fatigue model, as follows: $C=8.7 \times 10^{8}$, $\alpha=-2.0$ and $\beta=3.0$. The average results of the simulations of the 3 different samples are in very good agreement with the experimental results with above parameters. The envelopes of results of the DEM simulations depends on the microstructure of the ensembles (granulometry, void ratio, etc.), which is an important feature of discrete approaches. However, the optimization of these microstructural parameters were not object of the present study. 


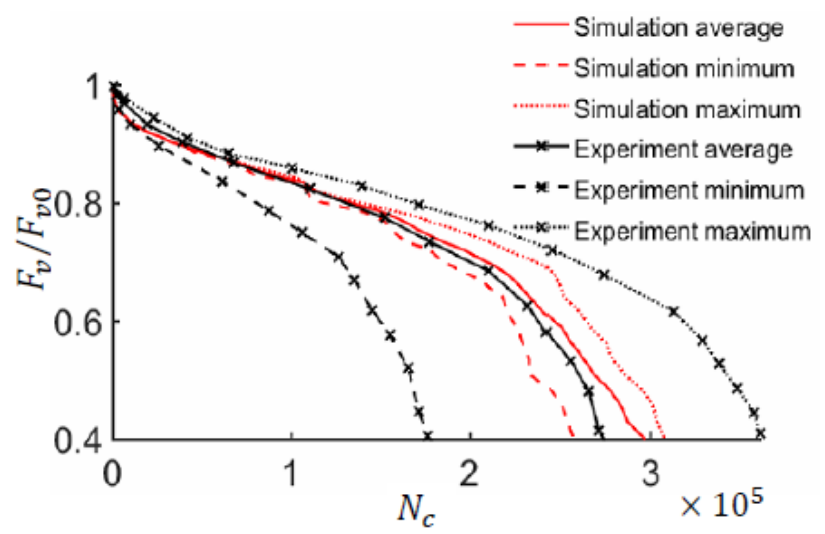

(a)

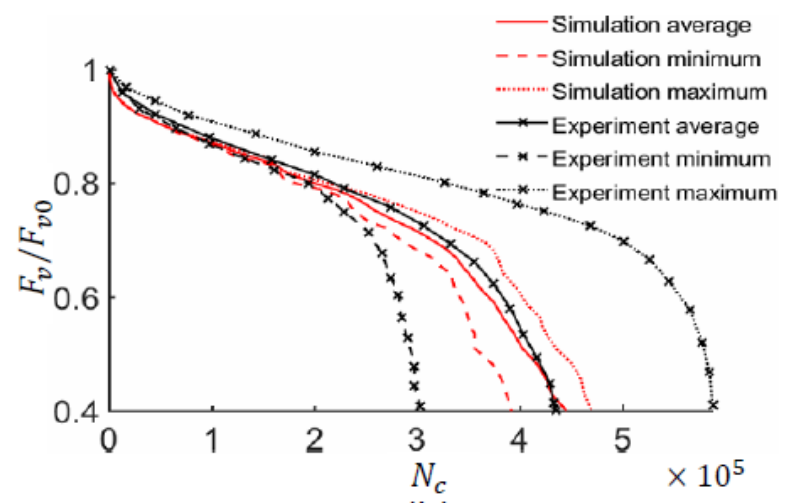

(b)

Fig. 5 Stiffness fraction $F_{v} / F_{v 0}$ as a function of the number of cycles $N_{C}$ for (a) $\varepsilon_{\max }=135 \mu \mathrm{m} / \mathrm{m}$ and (b) $\varepsilon_{\max }=150 \mu \mathrm{m} / \mathrm{m}$. Comparison between DEM simulations of 4PB tests and experiments of Arsenie $(2013,2017)$.

Each of the numerical samples presents different damage evolutions and strain localizations due to different particle distribution. The damage maps of each analyzed sample (Fig. 6) bring up some physical elements related to the variation of results. After a roughly homogeneous damage, mostly localized at the central span, the irregularity of the inner structure of the material induces different weak points. These points give rise to concentrated damage zones, physically behaving as cracks. The localization of these damage zones affects the sample response which explains most of the visible differences between the curves $F_{v} / F_{v 0}$ as a function of $N_{C}$.

All damage maps seem continuous near the supports which may indicate a neglectful effect of the deactivation of the damage around them as suggested in section 3.3. 


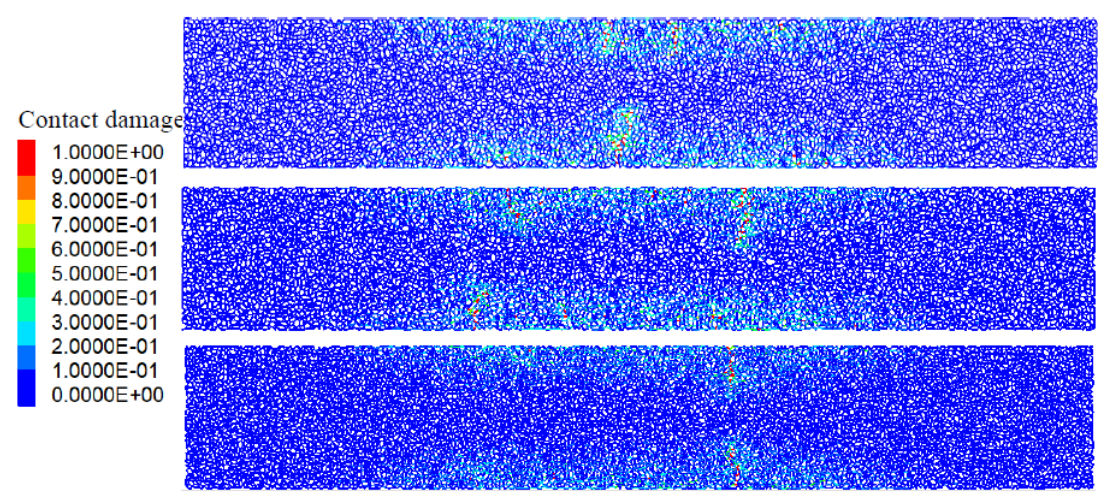

Fig. 6 Damage map for all the three samples for a stiffness fraction $F_{v} / F_{v 0}=0.4$.

\section{Effect of the glass fiber grids in $4 \mathrm{~PB}$ tests}

\subsection{Model of the reinforcements}

The cross section of the bending samples is presented in Fig. 7a. Considering the lack of precise information about the fatigue behavior of the contact between asphalt concrete and fiber glass, a perfect adhesion hypothesis is adopted. Consequently, the contribution of the yarns in 2D is taken as elastic axial reinforcements working under tension and compression (bars). The elastic stiffness $\mathrm{k}_{f}$ of one segment $i$ of a fiber glass reinforcement is determined by the expression:

$$
k_{f i}=E_{f} A_{f} / l_{i},
$$

where $E_{f}$ is the elastic modulus of the fiber grid and $A_{f}$ is the total cross section of fiber grid per layer and $l_{i}$ is the length of the segment. The effect of the bars are then taken into account on the discrete element model as additional contacts (Fig. 7b) connecting particles located at each layer, as shown in Fig. 7c. The contact properties are simply $E_{f}$ and $A_{f}$, whilst the length $l_{i}$ are automatically calculated based on the distance between the connected particles.

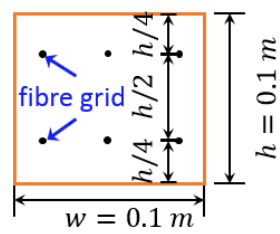

(a)

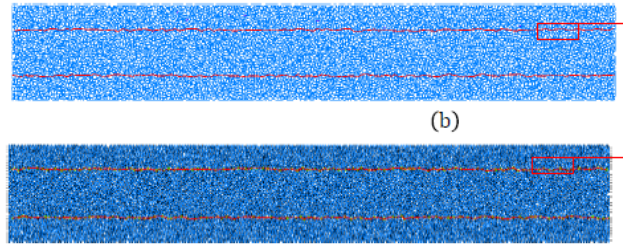

(c)

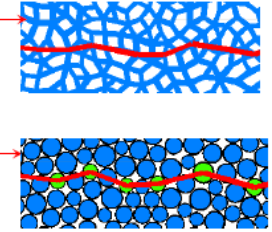

Fig. 7 (a) Cross section of the 4PB samples. Representation of the reinforcement bars (b) as additional contacts (c) connecting particles in the same layer. 


\subsection{Effect of the fiber reinforcements on the fatigue behavior tests}

The average evolution of the stiffness factor $F_{v} / F_{v 0}$ as a function of the number of cycles $N_{C}$ is shown in Fig. 8 for a strain amplitude of $\varepsilon_{\max }=150 \mu \mathrm{m} / \mathrm{m}$. The results of 3 samples with fibers compared to the previous results without reinforcements indicates an improvement of the fatigue life induced by the reinforcements. However, the global effect of the grids shown by the experiences of Arsenie $(2013,2017)$ is underestimated by the simulations. The contribution of the reinforcements seems to be more effective for $F_{v} / F_{v 0}<0.7$, when damage localized zones cross the fiber layer as observed by Liu (2019). On the experiments, the fiber grid improves the fatigue response since the beginning of the test, independently to any eventual damage level. This preliminary results suggests that a different mechanism may be associated to the fiber grid behavior, other than a simple axial reinforcement.

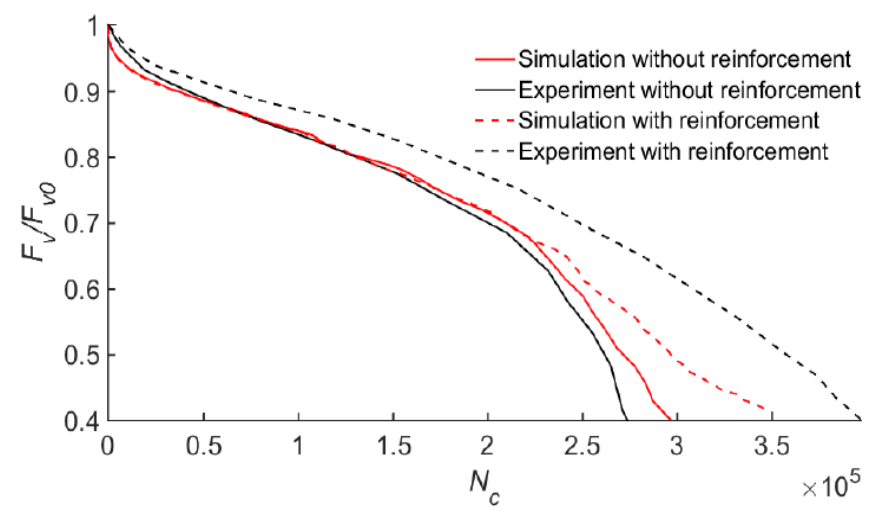

Fig. 8 Stiffness fraction $F_{v} / F_{v 0}$ as a function of the number of cycle $N_{C}$ in $4 \mathrm{~PB}$ tests $\left(\varepsilon_{\max }=\right.$ $150 \mu \mathrm{m} / \mathrm{m})$. Comparison between DEM simulations and the experiments of Arsenie $(2013,2017)$.

\section{Conclusions}

A fatigue damage model for asphalt concrete is adapted and implemented in a discrete element environment. A simple model describing material bulk behavior (phases $I$ and II) associated to the natural disordered microstructure of the discrete model is shown to be able to describe the entire fatigue behavior (phases $I, I I$ and $I I I$ ) in a sample scale. Phase III appears as a structure effect, which is characterized by a loss of homogeneity induced by the concentration of defects and a localization of the strain. The contribution of fiber grids as axial reinforcements on 4PB fatigue behavior is investigated. Experimental results points to a general improvement on the fatigue curves, whilst simulations seems to underestimate this effect of the fiber grids. The numerical results indicate that reinforcements are mostly activated when crossed by localized damaged zones.

The differences on experimental and numerical results suggest that grids do not act simply as axial reinforcements in asphalt concrete. Further analysis of the interface 
between asphalt concrete and fiber grids may provide more information and improve the modeling as shown in Liu (2019).

Acknowledgements The study is funded by China Scholarship Council.

\section{$7 \quad$ References}

Arsenie, I.M. (2013). Etude et modélisation des renforcements de chaussées à l'aide de grilles en fibre de verre sous sollicitations de fatigue. $\mathrm{PhD}$ thesis, Université de Strasbourg.

Arsenie, I.M, Chazallon, C., Duchez, J.L. (2017). Laboratory characterisation of the fatigue behaviour of a glass fibre grid-reinforced asphalt concrete using 4PB tests. Road Materials and Pavement Design 18(1), 168-180.

Bodin D., Pijaudier-Cabot, G., De La Roche, C., Piau, J.M., and Chabot, A. (2004). Continuum damage approach to asphalt concrete fatigue modeling. J. Eng. Mech. 130(6), 700-708.

Bodin, D. (2002). Modele d'endommagement cyclique: Application à la fatigue des enrobés bitumineux. PhD, University of Nantes (In French)

Ge, Z., Wang, H., Zhang, Q., and Xiong, C. (2015). Glass fiber reinforced asphalt membrane for interlayer bonding between asphalt overlay and concrete pavement. Construction and Building Materials 101, 918-925.

Guo, Q., Li, L., Cheng, Y., Jiao, Y., and Xu C. (2015) Laboratory evaluation on performance of diatomite and glass fiber compound modified asphalt mixture. Materials \& Design (19802015) $66,51-59$

$\mathrm{Hu}, \mathrm{X}$. and Walubita, L.F. (2009) Modelling tensile strain response in asphalt pavements: Bottom-up and/or top-down fatigue crack initiation. Road Mater. Pavement Des.10(1), 125-154.

Liu, G. (2019) Discrete element modelling of asphalt concrete reinforced with fiber glass grids. $\mathrm{PhD}$ thesis, University of Strasbourg, France.

Nguyen, M.L., Blanc, J., Kerzreho, J.P., and Hornych, P. (2013). Review of glass fibre grid use for pavement reinforcement and apt experiments at ifsttar. Road Materials and Pavement Design 14(sup1), 287-308.

Nguyen, N.H.T., Bui, H.H, Kodikara, J, Arooran, S., and Darve, F. (2019). A discrete element modelling approach for fatigue damage growth in cemented materials. International Journal of Plasticity 112, 68-88.

Paas, M.H.J.W. (1990). Continuum damage mechanics with an application to fatigue. $\mathrm{PhD}$ thesis, Eindhoven University of Technology, The Netherlands.

PFC 5.0 Itasca. (2014). User manual. In Itasca Consulting group, Inc. Washington DC, US.

Zhang, J., Shen, W.Q., Oueslati, A., and De Saxce, G. (2017). Shakedown of porous materials. International Journal of Plasticity 95, 123-141.

Zheng, M., Li, P., Yang, J. (2019). Fatigue character comparison between high modulus asphalt concrete and matrix asphalt concrete. Construction and Building Materials 206, 655-664. 